\title{
The environmental impact of technology innovation on WEEE management by Multi-Life Cycle Assessment
}

\author{
Bin Lu, Jingru Liu, Jianxin Yang*, Bo Li \\ State Key Laboratory of Urban and Regional Ecology, Research Center for Eco-Environmental Sciences, Chinese Academy of Sciences, P. O. Box 2871, \\ 18 Shuangqing Road, Haidian District, Beijing 100085, People's Republic of China
}

\section{A R T I C L E I N F O}

\section{Article history:}

Received 2 April 2014

Received in revised form

13 October 2014

Accepted 2 November 2014

Available online 8 November 2014

\section{Keywords:}

Technology innovation

WEEE

Multi-Life Cycle Assessment

Products replacement

\begin{abstract}
A B S T R A C T
Electrical and Electronic Equipment (EEE) technology innovation is strongly related to Waste Electrical and Electronic Equipment (WEEE) management strategies. It does not only effect the amount and speed of WEEE generation through products replacement, but it also exerts overall long-term impacts on the environmental performance of EEE system. Therefore, those impacts should be evaluated quantitatively. A concept framework is developed and applied in the case study of display product technology innovation, and a Multi-Life Cycle Assessment method is proposed to evaluate the environmental impacts of technology innovation on multi-generation systems. The study concludes that constant EEE technology innovation along with frequent product replacement may lead to acute fluctuations of WEEE generation and significant multi-generation products system environmental impacts. Hence, the product-oriented environmental policies, including waste management policies, should take technology innovation into consideration.
\end{abstract}

() 2014 Elsevier Ltd. All rights reserved.

\section{Introduction}

Electrical and Electronic Equipment (EEE) technology innovation has a strong correlation with Waste Electrical and Electronic Equipment (WEEE) management strategies. Rapidly evolving production technology and fast market penetration have the consequence that, newer products are now quickly replacing older ones, particularly for information and communications technology products such as personal computers and cellphones. Technology innovation not only impacts on the generation speed and quantity of WEEE, but it also exerts overall long-term environmental impacts.

\subsection{The impact of technology innovation on generation of WEEE}

Theoretical analysis and field investigation show that technology innovation is one of the most important factors for the shortening of EEE service lifespans, and leading to the generation of WEEE (Cooper, 2004; Granberg, 1997; Heiskanen, 1996; Kostecki, 1998; OECD, 1982; Van Nes and Cramer, 2006). Products incorporating new technologies are always developed to meet the continually growing functional and psychological needs of EEE consumers (Granberg, 1997; Kostecki, 1998). Hence, for EEE

\footnotetext{
* Corresponding author. Tel./fax: +86 1062849802.

E-mail address: yangjx@rcees.ac.cn (J. Yang).
}

producers, technology innovation promotes the market diffusion of new generation products while replacing older products.

From a macro point of view, technology innovation usually accelerates the Marketing Product Life Cycle (M-PLC) that includes the introduction, growth, maturity and decline phases (Cao and Folan, 2011). On the product level, products from different M-PLC phases will have different service times and different end-of-life routes, in their Product Life Cycles (PLC) that includes the mining of raw materials, products manufacturing, use, and end-of-life stages. For example, a product sold in the decline phase of M-PLC always has a shorter service lifespan than one sold in the introduction phase. Therefore, through M-PLC and PLC interactions, technology innovation affects the lifetime of EEE and generation of WEEE both directly and indirectly.

\subsection{Environmental performance of multi-generation products system}

Technology innovation has a long-term impact on EEE system. Several different generations of products coexist in the current EEE market with the same basic service function; for example, both cathode ray tubes (CRTs) and liquid-crystal displays (LCD) are used to display desktop computer output. This basic service does not consider detailed function parameters such as display brightness or resolution. 
Several studies showed that the technology cycle, which means the length of time that a product is at the leading edge of technology, is one of the most important factors in end-of-life strategies (Fujimoto and Ahmed, 2001; Pialot et al., 2012; Rose et al., 2002a, 2002b). A fast diffusion of new technology products means a low reusability of EEE components for the next generation of product (Kwak et al., 2011), and more open loop materials recycling. Lower component reuse or remanufacturing rate and more open loop recycling will inevitably change the environmental performance of the multi-generation product system, as closed loop recycling including remanufacturing or reuse is always considered as the higher level in the waste management hierarchy (King et al., 2006; Quariguasi-Frota-Neto and Bloemhof, 2012). Therefore, it is necessary to evaluate the environmental impacts of technology innovation so as to promote the sustainable WEEE management and eco-design in a more wide system.

However, traditional LCA method cannot fully evaluate such dynamic impact. With a static view, traditional LCA focuses one typical product or one typical generation of a given product. Although the recovered materials and components are generally included in the traditional LCA, their re-application or re-use processes in the new products or another industrial application are always out of the scope.

Hence, this study proposes a new method-Multi-Life Cycle Assessment (MLCA) - based on the concept of Multi-Products Life Cycle (MPLC), to evaluate the impact of technology innovation and products replacement on the environmental performance of multigeneration product systems.

The concept of MPLC emerged at the end of 1990s in the manufacturing engineering research field (Zhuang, 1999). MPLC does not only covers the life cycle of one product, but also includes the components reuse stage and materials recovery stage in the next generations of products (Caudill et al., 2001). Accordingly, the MLCA takes into consideration of the reuse and remanufacturing stages of products and their components in the next generation of products to expand the traditional LCA system boundary (Huang and $\mathrm{Xu}, 2005$ ). MLCA can help implement the eco-design concept in and between the generations of products at the stage of design and manufacturing (Huang and Xu, 2005). Moreover, it will be helpful for estimating the proper reuse time and number of cycles to minimize the environmental impacts (Chen and Liu, 2000). But, there is no general and solid MLCA methodology framework to date (Zhao et al., 2010).

The point of the proposed MLCA methodology is to evaluate the environmental performance of certain basic service provided by multi-generation products. The results can help push the materials recycling and components reuse between and in different generations of products. With a dynamic view, MLCA method will emphasize the material flows between different product generations and series, such as reusable components and recoverable materials.

Timescale is the significant difference between MLCA and traditional LCA, as the former takes both the market life time (product replacement) and product life cycle into consideration, while the later only deals with product life cycle.

\section{Methods development}

Technology innovation of EEE along with products replacement may firstly affect the lifespan of products, and then the generation speed and amount of WEEE. As a result, WEEE management will be influenced by the changes of WEEE generation. Further, the environmental performance of multi-generation products system will vary with the changes of WEEE recycling and reuse situation.

\subsection{WEEE estimation incorporating technology innovation}

This study develops an estimation framework based on market penetration model to evaluate the impacts of technology innovation on WEEE generation. Market diffusion models are employed to model and forecast different technology innovation scenarios, including the growth of new products and decline of old products. The market supply model is used to estimate WEEE generation (Widmer et al., 2005). And then, this model calculates the quantity of specific WEEE parts and materials, which cannot be used in the production of new products because of changes of product structure, or the old products because of decline of market share. The results do not only estimate the waste generation from different EEE generations, but also show the technology innovation effects on the WEEE end-of-life routes selection and the effects on the sensitive components and materials generated (Fig. 1).

To simulate the effects of technology innovation, it is necessary to combine market diffusion models with WEEE generation estimation models. Logistics curve and Fisher-Pry model were both used to estimate and forecast WEEE amounts in literature (Lam et al., 2012; Yang and Williams, 2009). However, none of these methods addressed the effects from products replacement, particularly in multi-generation product systems. There are several market diffusion models for product replacement including Gompertz model, Logistics Model, Bass model, Fisher-Pry model and Norton-Bass model. The Gompertz and Bass models are frequently used to estimate the product diffusion process for one generation of product (Bass, 1969). Compared with other models, the NortonBass model explicitly incorporates diffusion and substitution effects (Michalakelis et al., 2010) to simultaneously consider multiple technological generations (Norton and Bass, 1987). Therefore, both Bass and Norton-Bass model are used to describe the market diffusion processes in this framework.

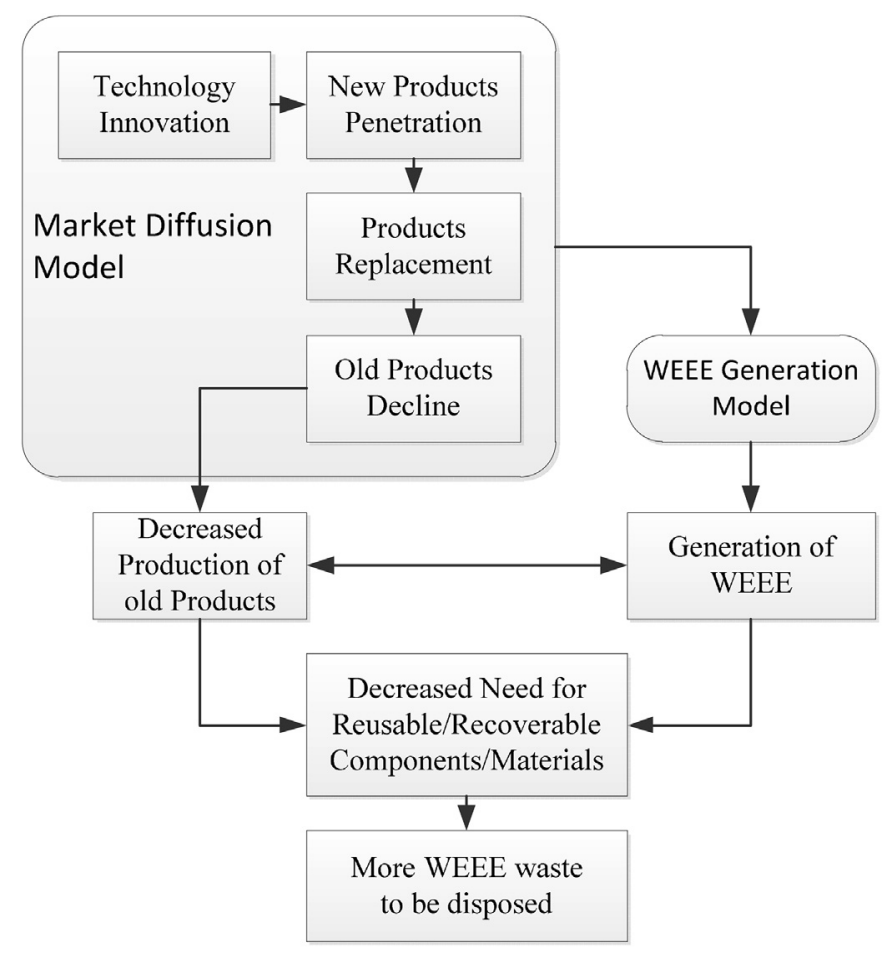

Fig. 1. Technology innovation impact on WEEE generation: evaluation framework. 
The main equation of Bass model is as following.

$N(t)=m\left[\frac{1-e^{-(p+q) t}}{1+\frac{q}{p} e^{-(p+q) t}}\right]$

$N(t)$ means the cumulative sale of target product; $p$ is the innovation coefficient; $q$ is the imitation coefficient; and $t$ is the time.

The Norton-Bass diffusion model of two generations is shown as follows:

$$
\begin{aligned}
t>0, \quad S_{1}(t) & =F_{1}(t) m_{1}-F_{2}\left(t-\tau_{2}\right) F_{1}(t) m_{1} \\
& =F_{1}(t) m_{1}\left[1-F_{2}\left(t-\tau_{2}\right)\right]
\end{aligned}
$$

$t>\tau_{2}, \quad S_{2}(t)=F_{2}\left(t-\tau_{2}\right)\left[m_{2}+F_{1}(t) m_{1}\right]$

Similarly, a three generation model is as follows:

$$
\begin{aligned}
t>0, \quad S_{1}(t) & =F_{1}(t) m_{1}-F_{2}\left(t-\tau_{2}\right) F_{1}(t) m_{1} \\
& =F_{1}(t) m_{1}\left[1-F_{2}\left(t-\tau_{2}\right)\right]
\end{aligned}
$$

$t>\tau_{2}, \quad S_{2}(t)=F_{2}\left(t-\tau_{2}\right)\left[m_{2}+F_{1}(t) m_{1}\right]\left[1-F_{3}\left(t-\tau_{3}\right)\right]$

$t>\tau_{3}, \quad S_{3}(t)=F_{3}\left(t-\tau_{3}\right)\left\{m_{3}+F_{2}\left(t-\tau_{2}\right)\left[m_{2}+F_{1}(t) m_{1}\right]\right\}$

where $S_{i}(t)$ refers to sales of the generation $i$ in time period $t, m_{1}$ refers to the potential for the first generation, $m_{2}$ and $m_{3}$ refers to the potential uniquely served by the second and third generation, and $\tau_{i}$ is the time at which the generation $i$ is introduced. The $F_{i}(t)$ equation is as follows:

$$
F_{i}(t)=\left[\frac{1-e^{-\left(p_{i}+q_{i}\right) t}}{1+\frac{q_{i}}{p_{i}} e^{-\left(p_{i}+q_{i}\right) t}}\right]
$$

\subsection{Multi-Life Cycle Assessment method}

The MLCA was developed to evaluate the environmental performance of multi-generation product life cycles that arise from technology innovation and product replacement. MLCA differ with conventional LCA method in the scope and functional unit definition, as well as the calculation method life cycle inventory, but not in other stages including life cycle impact assessment.

\subsubsection{Definition of scope and functional unit in MLCA}

The scope of MLCA contains a multi-generation product system where the products have the same basic function as shown in Fig. 2 (adapted from the figure in Zhuang (1999)). Each generation of product has complete life cycle stages: raw materials mining, manufacturing, use and end-of-life stage. Recovered materials and reused components are assumed to return to the original product or to the next generation of product.

This theoretical framework divides multi-generation products with the same basic function into two categories. The first category is the Generation. Different product generations have different working principles, manufacturing technologies and materials inputs, but the same basic function (for instance, the LCD display and CRT display). The second category is the Series. There are various series in the same product generation that differ only in functional parameters (for example, refrigerators with different refrigerants). Relatively, it is more probable to reassemble reusable components and to reuse recoverable materials among various products' series. In contrast, among different product generations, only recovered materials and no reusable components can be reused in the new

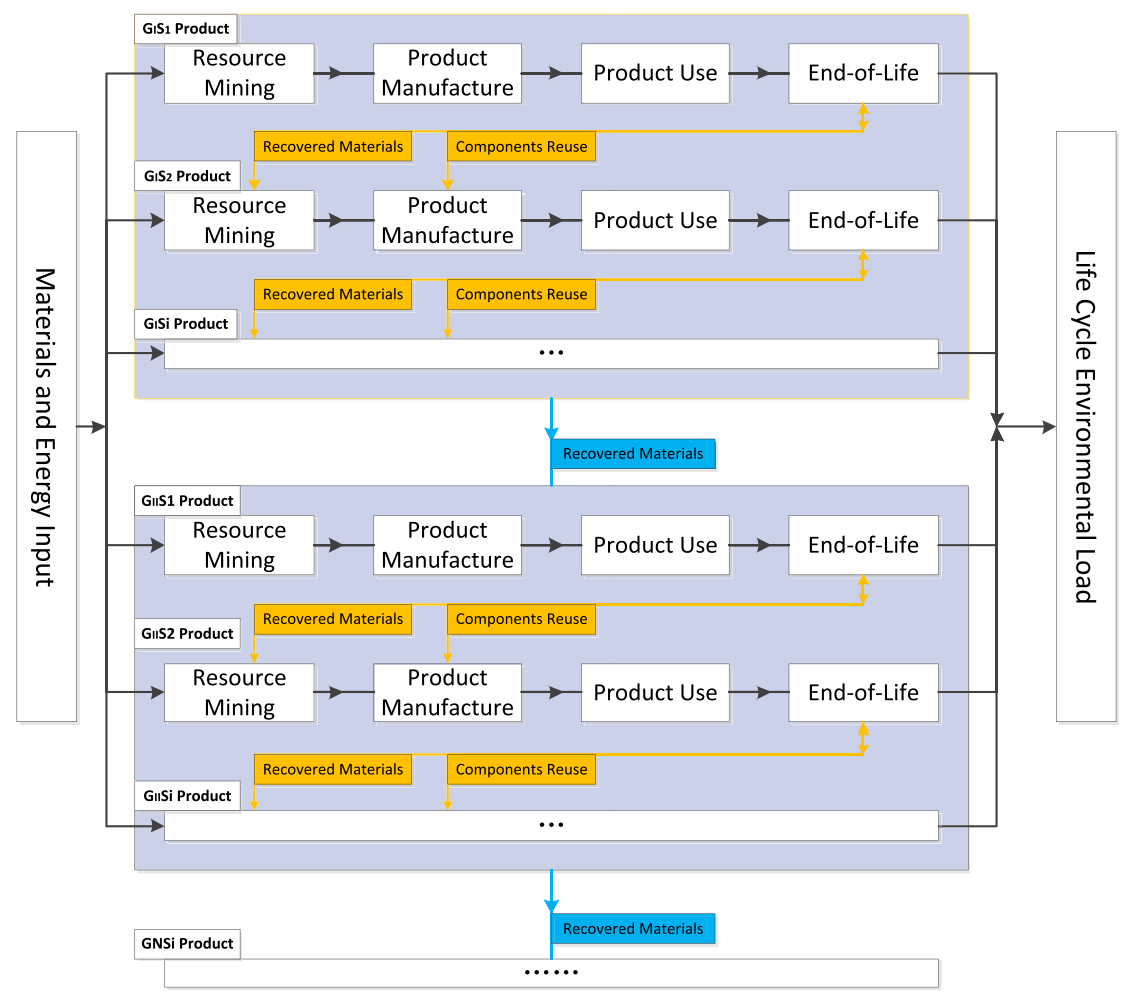

Fig. 2. MLCA study system. 
generation. Material flows among different product generations are shown in Fig. 2.

The functional unit of MLCA can be defined as "one basic service that multi-generation products can always provide". It is different from the functional unit in traditional LCA, which usually focus on one product that can provide the required functions.

\subsubsection{Integration model of life cycle inventory data in MLCA}

In MLCA, as the scope includes several life cycles of products, especially the components reuse and materials recovery stages among different generations, integration of life cycle inventory data should follow a standard process. Therefore, equations are developed for the integration of multi-life cycle inventory, in case of preventing duplicate calculation or inconsistent allocation.

The basic MLCA integration equation is developed from the MLCA framework discussed in 2.2.1, as follows:

$$
\begin{aligned}
\mathrm{EI}_{\text {system }}= & \sum_{I=1}^{N} \sum_{i=1}^{n}\left(\mathrm{EI}_{(I, i)}-\alpha \times\left(\mathrm{RCM}_{-} \mathrm{EI}_{(I, i)}+\mathrm{RMM}_{-} \mathrm{EI}_{(I, i)}\right)+\beta\right. \\
& \times\left(\mathrm{RCM}_{-} \mathrm{EI}_{(I, i-1)}+\mathrm{RMM}_{-} \mathrm{EI}_{(I, i-1)}\right)+\mathrm{RCR}_{-} \mathrm{EI}_{(I, i-1)} \\
& \left.+\mathrm{RMC}_{-} \mathrm{EI}_{(I, i-1)}-\mathrm{AC}_{-} \mathrm{EI}_{(I, i)}-\mathrm{AM}_{-} \mathrm{EI}_{(I, i)}\right)
\end{aligned}
$$

where, $I=1,2,3, \ldots, N ; i=1,2,3, \ldots, n$;

$\mathrm{EI}_{\text {system }}$ means the total environmental load of the multigeneration products system;

$\mathrm{EI}_{(I, i)}$ is the basic environmental load of $I$ generation $i$ series product, where it is assumed that no reusable components or recoverable materials are used in manufacturing stage and no components or materials are recovered in the end-of-life stage.

RCM_EI $(I, i)$ represents the environmental load in the manufacturing stage of the reusable components of product $I$ generation $i$ series that can subsequently be used in the $(i+1)$ series. $R C R \_E_{(I, i)}$ means the environmental load in the components remanufacture/repair process of the reusable components. Both RCM_EI $(I, i)$ and RCR_EI $(I, i)$ are set to zero, referring to different product generations. Additionally, some recovered materials that were particular to the former product generation but are of no use in the new generation are treated as reusable components.

$\operatorname{RMM}_{-} \mathrm{EI}_{(I, i)}$ stands for the environmental load in the manufacturing stage of recoverable materials of product $I$ generation $i$ series that can subsequently be used in the $(i+1)$ series. RMC_EI $I_{(I, i)}$ means the environmental load of the recoverable materials in the recovery stage.

$A C \_\mathrm{EI}_{(I, i)}$ is the avoided environmental load of required new components that are replaced by reusable components. AM_EI $(I, i)$ means the avoided environmental load of required new materials that are replaced by recoverable materials.

In the equation, $\alpha$ and $\beta$ are both the allocation coefficients of environmental load between different generations, and their sum equals 1 . It is assumed that both $\alpha$ and $\beta$ are equal to 0.5 in this study meaning that the reusable components and recovered materials environmental load are evenly allocated between the original and the next generation product.

Recycling rate is important in the LCA process. At the product or materials level, recycling rates of WEEE equals the concept "recovery targets" in EU WEEE Directive, which is calculated "by dividing the weight of the WEEE that enters the recovery or recycling/preparing for re-use facility, after proper treatment, by the weight of all separately collected WEEE for each category". In this MLCA calculation model for life cycle inventory data, the recycling rate is not listed in the equation, because recycling rates of different recovered materials are always not the same. This equation is not so detailed that different recovered materials are not separately considered.

From the parameters settings, the environmental load of the multi-generation products life cycle system could be shown as follows:

$$
\begin{aligned}
& \mathrm{EI}_{\text {system }}=\sum_{I=1}^{N} \sum_{i=1}^{n}\left(\mathrm{EI}_{(I, i)}-0.5\left(\mathrm{RCM}_{-} \mathrm{EI}_{(I, i)}+\mathrm{RMM}_{-} \mathrm{EI}_{(I, i)}\right)\right. \\
& +0.5\left(\mathrm{RCM}_{-} \mathrm{EI}_{(I, i)}+\mathrm{RMM}_{-} \mathrm{EI}_{(I, i)}\right)+\mathrm{RCR}_{-} \mathrm{EI}_{(I, i-1)} \\
& \left.+\mathrm{RMC}_{-} \mathrm{EI}_{(I, i-1)}-\mathrm{AC}_{-} \mathrm{EI}_{(I, i)}-\mathrm{AM}_{-} \mathrm{EI}_{(I, i)}\right)
\end{aligned}
$$

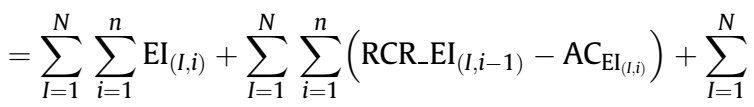

$$
\begin{aligned}
& \times \sum_{i=1}^{n}\left(\mathrm{RMC}_{-} \mathrm{EI}_{(I, i-1)}-\mathrm{AM}_{-} \mathrm{EI}_{(I, i)}\right)
\end{aligned}
$$

In formula (9), the environmental load of the multilife cycle system is composed of three parts. The first is the basic product environmental load; the second is the difference between the environmental load of the new materials and recovered materials; and the third is the difference between the new components and the reused components. Since the basic design and manufacturing of products can always be assumed as fixed in the same product generation, the environmental load of multi-life cycle systems differ in the latter two parts. In other words, an increase in the flows of reusable products and recoverable materials leads to a decrease in the environmental load of products in their end-of-life stage, and a lower environmental load of the multi-generation products system.

In the MLCA model, time is still an important factor for components reuse and materials recovery between different product generations and series. The $t_{i}$ is the replacement lifespan of series $i$ product. $T_{I}$ stands for the market lifetime of Generation I product, which is the period when the target products have a significant market share.

In the MLCA formula, the quantity of reused components and recovered materials are related to both time types. Therefore, it needs to give coefficients to RCR_EI $(I, i)$ and RMC_EI $I_{(I, i)}$. The coefficient of RCR_EI $(I, i-1)$ is $p(0 \leq p \leq 1)$, and the coefficient of $\mathrm{RMC}_{-} \mathrm{EI}_{(I, i-1)}$ is $q(0 \leq q \leq 1)$, therefore,

$$
\begin{aligned}
& {\operatorname{RCR} \_E I_{(I, i)}}=p * \mathrm{RCR} \_E I_{(I, i)_{\max }} \\
& {\mathrm{RMC} \_\mathrm{EI}_{(I, i)}}=q * \mathrm{RMC} \_\mathrm{EI}_{(I, i)_{\max }}
\end{aligned}
$$

The max is the environmental load of reusable components and recoverable materials of Generation $I$ products.

The $p$ and $q$ are determined by the relationship of $T_{I}$ and $t_{i}$ :

If $t_{i}>T_{I}$, i.e. when product GISi reaches its replacement lifetime, the GI products have also been phased out from the market. So, $p=0$, and $q$ is a fixed value:

Total Quantity of recoverable materials which is used in $\mathrm{G}(I+1)$ Product

$q=\frac{\text { Total Quantity of recoverable materials of GI which can beused in } G(I+1) \text { Product }}{\text { The }}$ 
If $t_{i}<T_{I}$, then when product GISi is replaced, the GI products still have a significant share in the market. There are two scenarios under this condition. If the production quantity is greater than the obsolete items, both $p$ and $q$ will equal 1, i.e., all the reused components and recovered materials can be put into GI product manufacturing stage. If the production quantity is less than the obsolete items.

\section{Case study}

LCD products have developed rapidly in recent years because of advantages over the CRT in the context of light weight, higher resolution and contrast, as well as lower energy consumption. However, CRTs are much cheaper than LCDs. As a result, they still have some market share. In 2011, the CRT Television still had $10.24 \%$

$p=\frac{\text { Production quantity of the same generation at the target period }}{\text { Obsolete quantity of Si product in the target period }}$

Total recovered materials from GI products used in $G(I+1)$ products

$q=p+\frac{\text { Total recovered materials from } \mathrm{Gl} \text { products used in } \mathrm{G}(I+1) \text { products }}{\text { Total recovered materials from GI products available for } \mathrm{G}(I+1) \text { products }}$

Therefore, the MLCA formula can be derived as follows:

$$
\begin{aligned}
& \mathrm{EI}_{\text {system }}=\sum_{I=1}^{N} \sum_{i=1}^{n} \mathrm{EI}_{(I, i)}+\sum_{I=1}^{N} \sum_{i=1}^{n}\left(\mathrm{RCR} \_\mathrm{EI}_{(I, i-1)}+\mathrm{RMC}_{-} \mathrm{EI}_{(I, i-1)}\right. \\
& \left.-\mathrm{AC}_{\mathrm{EI}_{(I, i)}}-\mathrm{AM}_{-} \mathrm{EI}_{(I, i)}\right) \\
& =\sum_{I=1}^{N} \sum_{i=1}^{n} \mathrm{EI}_{(I, i)}+\sum_{I=1}^{N} \sum_{i=1}^{n}\left(p \times \mathrm{RCR}_{-} \mathrm{EI}_{(I, i-1) \max }\right. \\
& \left.-\mathrm{AC}_{\left.\mathrm{EI}_{(, i, i}\right)}\right)+\sum_{I=1}^{N} \sum_{i=1}^{n}\left(q \times \mathrm{RMC}_{-} \mathrm{EI}_{(I, i-1) \max }\right. \\
& \text { - AM_EI }(I, i))
\end{aligned}
$$

\subsubsection{Procedures of $M L C A$}

As discussed above, MLCA can follow the procedures shown in Fig. 3.

(1) Definition of the goal and the scope of MLCA. The scope, especially the time scope, will be expanded to incorporate several series and generations of products. Then the basic function of different generations of products will be defined. And as the special part, materials flows and components flows among generations will be identified.

(2) Life cycle inventory analysis. Life cycle data of multigeneration products needs to be collected. Especially, products market life time (sales data) and product lifespan of all studied products shall be collected or estimated. Then the key parameters of MLCA integration model will be calculated. And the inventory analysis similar to the traditional LCA will be operated.

(3) Life cycle impact assessment. Generally, impact assessment in MLCA is the same as the classical LCA.

(4) Interpretation. In the interpretation stage of MLCA, technology innovation along with products replacement will be all discussed. share in China's television market, competing with LCD and PDP (Plasma Display Panel) television, as shown in Table 1. As the present situation shows, the display technologies innovation, from CRT to LCD, provides a proper case for assessing the impacts of technology on WEEE system. Hence, the replacement of CRT by LCD is used to apply the theoretical models developed above.

\subsection{Technology innovation oriented estimation of waste CRT glass}

The substitution of CRT by LCD results in a faster generation of waste CRT glass. Waste CRT glass is mainly composed of funnel glass and panel glass. Panel glass contains small lead amount and can thus be treated like the common glass (Li and Wen, 2006). Funnel glass, however, contains a higher percentage of lead that it is required to be treated as hazardous waste in China. The best available recycling technology for funnel glass is to be returned to the CRT manufacturing process, as a type of closed loop recycling. However, the LCD market share increased so rapidly that the production and

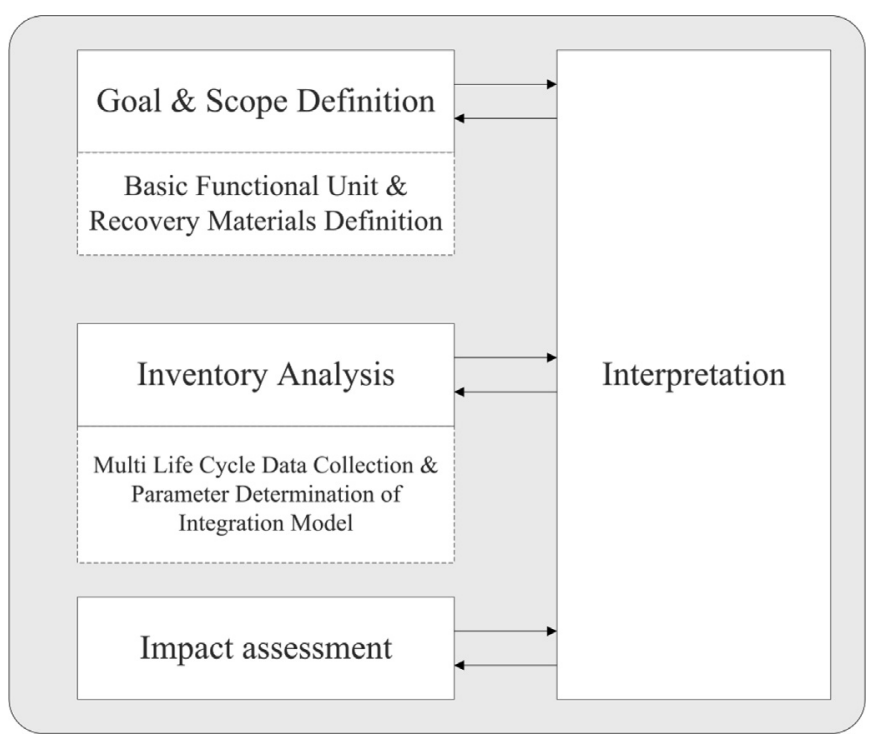

Fig. 3. A general methodological framework for MLCA (adapted from ISO 14040). 
Table 1

Domestic sales of LCD and CRT products in China.

\begin{tabular}{llllll}
\hline Year & $\begin{array}{l}\text { Annual sales } \\
\text { of CRT colored } \\
\text { TV (unit) }\end{array}$ & $\begin{array}{l}\text { Annual sales } \\
\text { of LCD TV } \\
\text { (unit) }\end{array}$ & $\begin{array}{l}\text { Annual sales } \\
\text { of PDP TV } \\
\text { (unit) }\end{array}$ & $\begin{array}{l}\text { Annual sales } \\
\text { of CRT } \\
\text { displays } \\
\text { (unit) }\end{array}$ & $\begin{array}{l}\text { Annual sales } \\
\text { of LCD } \\
\text { displays } \\
\text { (unit) }\end{array}$ \\
\hline 1995 & $15,778,000$ & & & & \\
1996 & $17,263,468$ & & & & \\
1997 & $22,079,332$ & & & $1,639,129$ & \\
1998 & $33,429,819$ & & & $3,294,400$ & \\
1999 & $34,226,618$ & & $8,945,101$ & \\
2000 & $28,218,000$ & & & $8,680,000$ & \\
2001 & $32,422,267$ & & $9,430,000$ & 540,000 \\
2002 & $33,303,151$ & & $11,980,000$ & 444,000 \\
2003 & $45,231,473$ & 692,205 & 95,251 & $20,847,961$ & $8,288,541$ \\
2004 & $51,113,505$ & $1,118,500$ & 119,600 & $14,455,700$ & $4,029,400$ \\
2005 & $51,221,730$ & $2,346,309$ & 539,299 & $10,160,739$ & $11,926,412$ \\
2006 & $42,696,523$ & $5,023,116$ & 272,029 & $10,573,639$ & $19,722,300$ \\
2007 & $42,239,297$ & $9,947,934$ & 533,053 & $7,809,205$ & $34,406,629$ \\
2008 & $36,453,270$ & $18,161,099$ & $2,248,823$ & $4,106,595$ & 53.087382 \\
2009 & $15,118,340$ & $50,072,372$ & $1,296,944$ & $3,751,294$ & 47.676 .749 \\
2010 & $10,814,806$ & $77,561,901$ & $1,649,514$ & 789,823 & 57.069 .096 \\
2011 & $8,446,132$ & $70,609,658$ & $3,120,606$ & 426,000 & 58.938 .223 \\
\hline
\end{tabular}

Data sources: Yearbook of China Information Industry, China Statistical Yearbook of Information Industry.

sale of CRT experienced a severe decrease, meaning a dramatic drop in funnel glass requirements. Hence, the generation of waste funnel glass is connected with technology innovation frequencies.

\subsubsection{Aim, scope and assumptions}

This case study aims to evaluate the impact of different replacement speeds on the generation amount and recycling routes of waste CRT glass. Three scenarios are developed to simulate the replacement process at different speeds. The primary assumptions and parameters for case study are listed as follows:

1) A CRT display weighs $15 \mathrm{~kg}$ per unit on average, while the CRT television averages at $25 \mathrm{~kg}$. The tube glass generally comprises $55 \%-65 \%$ of the total CRT product weight simplified here to $60 \%$.

2) Only funnel glass and panel glass are taken into consideration in this case study. The neck glass with high lead rates and the solder parts are included as funnel glass. Funnel glass is generally $33-35 \%$ of the total CRT tube weight while the panel glass is $65 \%-67 \%$ (Gregory et al., 2009). This study uses $33 \%$ and $67 \%$ as the respective settings.

3) The study assumes that similar reused glass technologies are employed in all CRT manufacturing, meaning that the reused glass can be applied in different production processes. One patent from a large CRT tube manufacturer shows that reused funnel glass should not exceed $30 \%$ of the total weight (Li et al., 2007).

4) In this case, the 1st generation is the CRT product and the 2nd generation is the LCD product. In the television replacement process, PDP televisions are also targeted in technology innovation along with colored CRT and LCD televisions in Scenario B and $C$. Although the sale of PDP television has been proved to be declined recently and it cannot be taken as the 3rd generation technically, in the recent 10 years, the PDP television sales were so large that they partly affected the assumed television replacement process, so in this study the PDP television is still taken into consideration in the diffusion models.

\subsubsection{Scenario settings: different technology innovation speeds}

\section{(1). Scenario A: no technology innovation}

Scenario A assumes no LCD technology and the penetration of CRT products follows the Bass model curve. In other words, the CRT
Table 2

Average physical lifespans of different TV types.

\begin{tabular}{lll}
\hline Types of TV & $\begin{array}{l}\text { Physical lifespans as reference } \\
\text { (hours) }\end{array}$ & $\begin{array}{l}\text { Key lifetime sensitive } \\
\text { parts }\end{array}$ \\
\hline CRT & $5000-10,000$ & Cathode ray tube \\
PDP & $25,000-30,000$ & Luminopher part \\
LCD & $50,000-60,000$ & Back light \\
\hline
\end{tabular}

Table 3

Bass model parameters for penetration of CRT products in Scenario A.

\begin{tabular}{lrr}
\hline Parameters & CRT display & CRT colored TV \\
\hline$m$ & $731,850,251$ & $1,383,475,977$ \\
$p$ & 0.004 & 0.012 \\
$q$ & 0.323 & 0.143 \\
$R^{2}$ & 0.995 & 0.998 \\
\hline
\end{tabular}

service lifespan is assumed to be only determined by the designed physical lifespan in this scenario, instead of other factors (like the storage time/reuse time etc.). The CRT physical lifespan is assumed to be 10 years according to the Chinese National Standardization Committee by-laws of home appliances safe service life (shown in Table 2).

The penetration process is assumed as the Bass model curve (Equation (1)). In reality, LCD products began to replace CRT products in China on a large scale since 2003. Hence, to avoid the impacts of LCD sales on CRT diffusion data, the Bass model parameters are estimated based on pre-2003 CRT sales data. The nonlinear least square method is used to estimate Bass model parameters of CRT display and CRT color TV, as shown in Table 3.

CRT products sales for 2012-2020 are calculated based on the estimated Bass model parameters.

\section{(2) Scenario B: actual technology innovation}

In Scenario B, the generation of waste CRT glass is estimated based on actual domestic LCD and CRT product sales data. The LCD and CRT products sales data 1999-2010 shown in Table 1 are used to estimate the model parameters.

The LCD and CRT displays used a two-generation diffusion model (Equations (2) and (3) in part 2.1). Similarly, a threegeneration model is used to depict the television replacement process (Equations (4)-(6)). The Genetic Algorithm method is used to estimate the Norton-Bass model parameters (Table 4).

\section{(3). Scenario C: fast technology innovation}

In Scenario C, it is assumed that fast penetration of LCD products would shorten the replacement lifetime of CRT products to 5 years from 2003 to 2012. The other assumptions remain the same as in Scenario B, as well as the diffusion models.

\subsubsection{Results}

The results of the three scenarios shown in Fig. 4 indicate that the transfer from CRT to LCD will greatly affect in the amount and

Table 4

Estimated Norton-Bass model parameters in Scenario B.

\begin{tabular}{llllll}
\hline $\begin{array}{l}\text { Model } \\
\text { parameters }\end{array}$ & CRT display & LCD display & CRT colored TV & LCD TV & PDP TV \\
\hline$m$ & $202,957,999$ & $12,303,966$ & $197,464,999$ & $2,766,495$ & 105,778 \\
$p$ & 0.013 & 0.007 & 0.148 & 0.001 & 0.140 \\
$q$ & 0.670 & 0.639 & 0.196 & 0.324 & 0.276 \\
$R^{2}$ & 0.981 & 0.981 & 0.954 & 0.954 & 0.954 \\
\hline
\end{tabular}




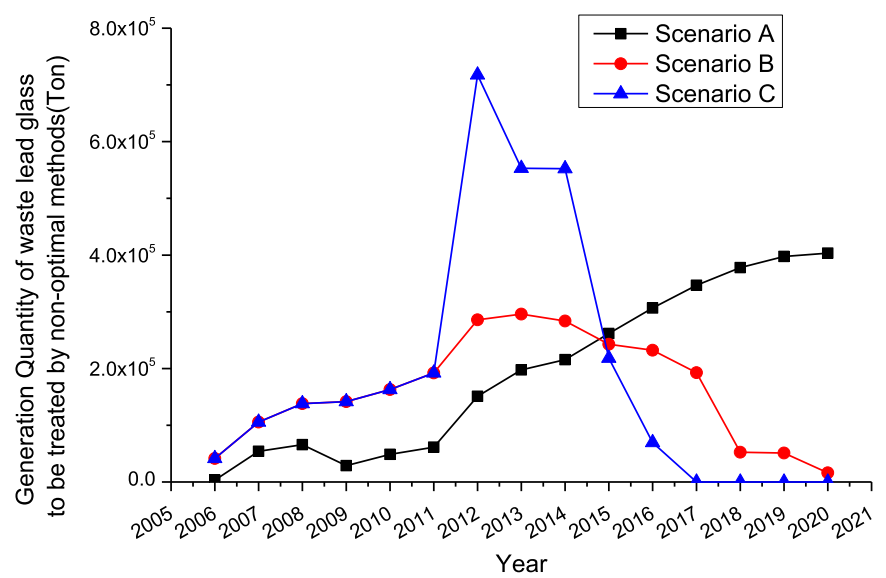

Fig. 4. Waste CRT funnel glass to be treated by alternative non-optimal method in the three scenarios.

speed of waste CRT glass generation. If no LCD product existed, the generation of waste CRT funnel glass would increase evenly, as the result of Scenario A shows. In the actual situation (Scenario B), the generation of waste CRT funnels glass increases then decreases, but generally smoothly. The maximum annual generation quantity reaches 300,000 tons. In fact, in Scenario B the quantity of waste CRT glass to be disposed of in other ways begins to dramatically increase from 2010. In Scenario C, Prior to 2012, waste CRT glass generation follows a similar pattern to Scenario B. However, from the year 2013 the generation of waste CRT funnel glass significantly increases to 717,512 tons. Moreover, CRT would have no market share from 2012 with no waste glass needed in the CRT manufacturing industry; hence, all waste CRT glass would be transferred to other end-of-life routes.

The results show that product replacements, as the direct result of technology progress, greatly affect the generation of WEEE. If the replacement process is extremely fast, the obsolete products will increase explosively in a short time period and subsequently decrease. The explosive increment will place large pressure on the waste recycling system, which may lead to a lot of disposed rather than recycled products, and the subsequent speedy decrease may leave treatment facilities idle for a long period. Thus, steady WEEE generation is beneficial to sustainable waste management and the construction of recycling systems.

\subsection{MLCA of computer display products}

\subsubsection{Aim, scope and assumptions}

This case study aims to evaluate the environmental impact of different technology innovation frequencies on multi-generation computer display systems.

Desktop computer displays, including CRT and LCD, are chosen as the target MLCA products. The functional unit is set as one display that can realize the basic display function for the desktop computer. The time period is set as 2000-2020.

The system boundary is shown in Fig. 5. Following spherical and flat screen CRTs, the LCD is now the mainstream desktop computer display product. Limited by data availability, the CRT and LCD displays are separately taken as an entire generation, rather than as several series, such as spherical and flat screen CRTs in the CRT category, and Super Twisted Nematic (STN), Thin Film Transistor (TFT) and Light Emitting Diode (LED) in the LCD category.

It is necessary in MLCA to identify the reusable components inside the same generation and recoverable materials between different generations. In this case, the CRT glass including panel glass and funnel glass is chosen as the reusable component in the CRT generation, since it can be reused in different CRT series easily. Copper is taken as the recoverable material inside and between the different CRT and LCD generations. Although plastics such as ABS in CRT displays can also be reapplied in LCD displays in theory, but the ABS recovery technology at present cannot change the recovered ABS to meet the technology requirement of LCD display, and strict environmental regulations such as RoHS directive also prevent the recycling of degraded ABS. Other metals like steel is small in the

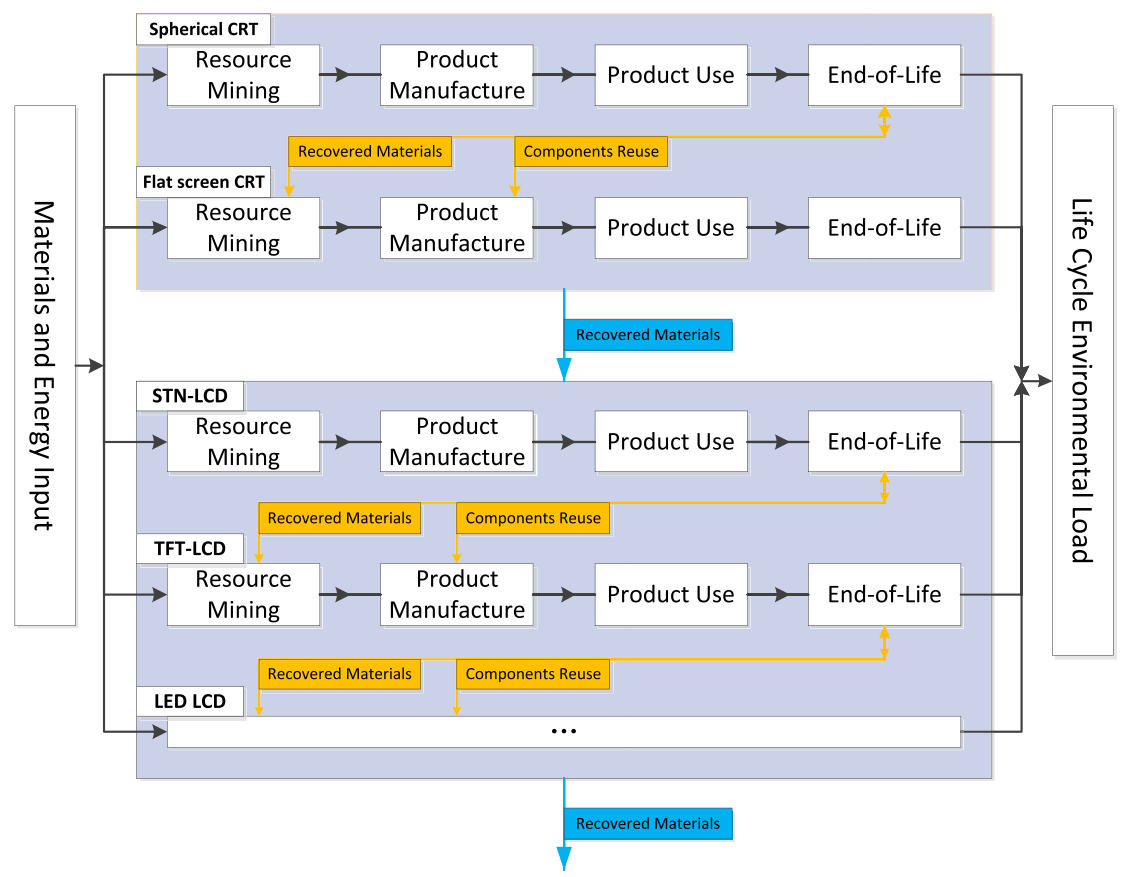

Fig. 5. MLCA system boundary of the display products system. 
materials composition of CRT and LCD compared to copper, so they are also excluded from calculating the recoverable materials between CRT and LCD.

The basic scenario settings are as follows:

1) During operation, CRT displays generally use $90-110 \mathrm{w}$ of power, while LCDs use $30-40 \mathrm{w}$. For simplification here, it is assumed that the CRT operating power is $100 \mathrm{w}$ and the LCD is $35 \mathrm{w}$.

2) It is assumed here that the "Electric Heating Wire SeparationHigh Pressure Water Cleaning-Shredding" patented technology is used for CRT end-of-life (Walk, 2009). The environmental load of the glass recycling process is set as RCR_EI $I_{\text {glass }}$, and the environmental load of original glass manufacturing process is AC_EI glass.

3) Copper is used in the cables and printed circuit boards of both CRT and LCD displays. One 17-inch CRT display contains an average of $890 \mathrm{~g}$ of copper ( $\mathrm{Li}$ and Wen, 2006), while one 17-inch LCD display contains an average of $110 \mathrm{~g}$ of copper (Hester and Harrison., 2008). The environmental load of copper recycling process is $\mathrm{RMC} \mathrm{EI}_{\mathrm{Cu}}$, and the original production process is AM_EI $\mathrm{Cu}$

4) In this case, recycling rates of WEEE are set as 95\% for all materials, including plastics, metals.

The MLCA data sources are listed in Table 5. Most data in this study is from field investigation in the recycling plants and existed databases, such as EcoInvent database and basic LCA database developed in CAS. But the data in the LCD recycling process is modeled based on literature for Chinese LCD treatment processes (Guo et al., 2011; Liu et al., 2014; Wu Jian and Feng, 2013), because there is still no formal plants to recycle the LCD products by large scale.

The Eco-Indicator 99 (EI99) is chosen as the life cycle impact assessment method, with one minor change. Nitrogen trifluoride $\left(\mathrm{NF}_{3}\right)$, which has a high global warming potential and is usually used in LCD production, is added to the EI99 climate change assessment category (Forster et al., 2007).

\subsubsection{MLCA scenarios}

Three scenarios are developed based on the use and replacement frequency of different display products to evaluate the environmental impacts of product replacement in the multi-generation life cycle system.

The developed scenarios are different in terms of products quantity, use intensity, and replacement times, as shown in Table 6. Between 2000 and 2020, it is assumed that there are three display products in Scenario 1 (basic replacement speed), four products in Scenario 2 (fast replacement speed), two products in Scenario 3 (slow replacement speed). The products are used for 1500, 2400

Table 5

MLCA data sources of displays.

\begin{tabular}{|c|c|c|}
\hline Data Categories & Data sources & Characteristics \\
\hline CRT manufacturing & $\begin{array}{l}\text { Environmental impact } \\
\text { assessment report from } \\
\text { manufacturers }\end{array}$ & Field investigation \\
\hline CRT recycling & Field investigation & Field investigation \\
\hline LCD manufacturing & Ecolnvent database & Literature \\
\hline LCD recycling & $\begin{array}{l}\text { Literature (Guo et al., 2011; } \\
\text { Liu et al., 2014; Wu Jian and } \\
\text { Feng, 2013) }\end{array}$ & $\begin{array}{l}\text { Literature and theoretic } \\
\text { models }\end{array}$ \\
\hline Background data & RCEES basic database & $\begin{array}{l}\text { Field investigation and } \\
\text { literature }\end{array}$ \\
\hline
\end{tabular}

Table 6

Key assumptions in three scenarios.

\begin{tabular}{|c|c|c|c|c|c|c|}
\hline & $\begin{array}{l}\text { 1st } \\
\text { Display } \\
\text { product }\end{array}$ & $\begin{array}{l}\text { 2nd } \\
\text { Display } \\
\text { product }\end{array}$ & $\begin{array}{l}\text { 3rd } \\
\text { Display } \\
\text { product }\end{array}$ & $\begin{array}{l}\text { 4th } \\
\text { Display } \\
\text { product }\end{array}$ & $\begin{array}{l}\text { Use } \\
\text { frequency } \\
\text { (hours/year) }\end{array}$ & $\begin{array}{l}\text { Replacement } \\
\text { time point (year) }\end{array}$ \\
\hline Scenario 1 & CRT & LCD & LCD & - & 1500 & 2007, 2014, 2020 \\
\hline Scenario 2 & CRT & CRT & LCD & LCD & 2400 & $\begin{array}{l}2005,2010,2015, \\
2020\end{array}$ \\
\hline Scenario 3 & CRT & LCD & - & - & 900 & 2010 \\
\hline
\end{tabular}

and $900 \mathrm{~h}$ respectively per year. The $p$ and $q$ parameters of the three scenarios are calculated based on equation in 2.2.2 (Table 7).

The environmental load of the Scenario 1 display products system can be calculated as:

$$
\begin{aligned}
& \mathrm{EI}_{\text {Display }}=\mathrm{EI}_{\mathrm{CRT}}+2 \times \mathrm{EI}_{\mathrm{LCD}}+\left(p_{1} \times \mathrm{RCR}_{-} \mathrm{EI}_{\text {glass }}+q_{1}\right. \\
& \left.\times \mathrm{RMC}_{-} \mathrm{EI}_{\mathrm{CRT} \text { _copper }}-\mathrm{AM}_{-} \mathrm{EI}_{\mathrm{LCD}_{-} \text {copper }}\right)+\left(p_{2}\right. \\
& \times \mathrm{RCR}_{-} \mathrm{EI}_{\text {unknown }}+\mathrm{RMC}_{-} \mathrm{EI}_{\mathrm{LCD} \_ \text {copper }}-p_{2} \\
& \left.\times \mathrm{AC}_{-} \mathrm{EI}_{\text {unknown }}-\mathrm{AM}_{-} \mathrm{EI}_{\mathrm{LCD} \_ \text {copper }}\right)
\end{aligned}
$$

The RCR_EI $I_{\text {unknown }}$ and AC_EI $I_{\text {unknown }}$ mean the environmental load in both the end-of-life and original production stages that can be used in the next generation of LCD display. However, because there are no data on the future reusable components, both parameters are assumed to be zero in this case.

In Scenario 2, the environmental load of the display products system is calculated as:

$$
\begin{aligned}
& \mathrm{EI}_{\text {Display }}=2 \times \mathrm{EI}_{\mathrm{CRT}}+2 \times \mathrm{EI}_{\mathrm{LCD}}+\left(p_{1} \times \mathrm{RCR}_{-} \mathrm{EI}_{\text {glass }}+q_{1}\right. \\
& \left.\times \mathrm{RMC}_{-} \mathrm{EI}_{\mathrm{CRT}_{\text {copper }}}-\mathrm{AC}_{-} \mathrm{EI}_{\text {glass }}-\mathrm{AM}_{\text {_EI }} \mathrm{CRT}_{\text {CRcopper }}\right) \\
& +\left(p_{2} \times \mathrm{RCR}_{-} \mathrm{EI}_{\text {glass }}+q_{2} \times \mathrm{RMC}_{-} \mathrm{EI}_{\mathrm{CRT} \text { _copper }}\right. \\
& \left.-\mathrm{AM}_{-} \mathrm{EI}_{\text {LCD_copper }}\right)+\left(p_{3} \times \mathrm{RCR}_{-} \mathrm{EI}_{\text {unknown }}+q_{3}\right. \\
& \times \text { RMC_EI } I_{\text {LCD_copper }}-\mathrm{AC}_{-} \mathrm{EI}_{\text {unknown }} \\
& \text { - AM_EI } \left.I_{\text {LCD_copper }}\right)
\end{aligned}
$$

In Scenario 3, the environmental load of the display products system is calculated as:

$$
\begin{aligned}
\mathrm{EI}_{\text {Display }}= & \mathrm{EI}_{\mathrm{CRT}}+\mathrm{EI}_{\mathrm{LCD}}+\left(p_{1} \times \mathrm{RCR}_{-} \mathrm{EI}_{\text {glass }}+q_{1} \times \mathrm{RMC}_{-} \mathrm{EI}_{\text {copper }}\right. \\
& \left.-\mathrm{AM}_{-} \mathrm{EI}_{\text {copper }}\right)
\end{aligned}
$$

\subsubsection{Results}

The environmental load in the manufacturing and recovery stages of copper and CRT glass are shown in Fig. 6 and Fig. 7.

The results show that the CRT glass and copper environmental load is much smaller than that of the entire product system. Generally, CRT glass is considered to have a high environmental load because of its high lead content, and copper is always known as one of the most valuable materials in the WEEE recycling industry (Walk, 2009). However, in the formal WEEE treatment routes operating under national laws, neither the environmental load of CRT glass nor copper is sufficiently high to change the basic

Table 7

Scenario parameters.

\begin{tabular}{lllllll}
\hline Scenarios & $p 1$ & $q 1$ & $p 2$ & $q 2$ & $p 3$ & $q 3$ \\
\hline Scenario 1 & 1 & 1 & 0 & 1 & - & - \\
Scenario 2 & 1 & 1 & 0.15 & 0.27 & 0 & 1 \\
Scenario 3 & 0.15 & 0.27 & - & - & - & - \\
\hline
\end{tabular}




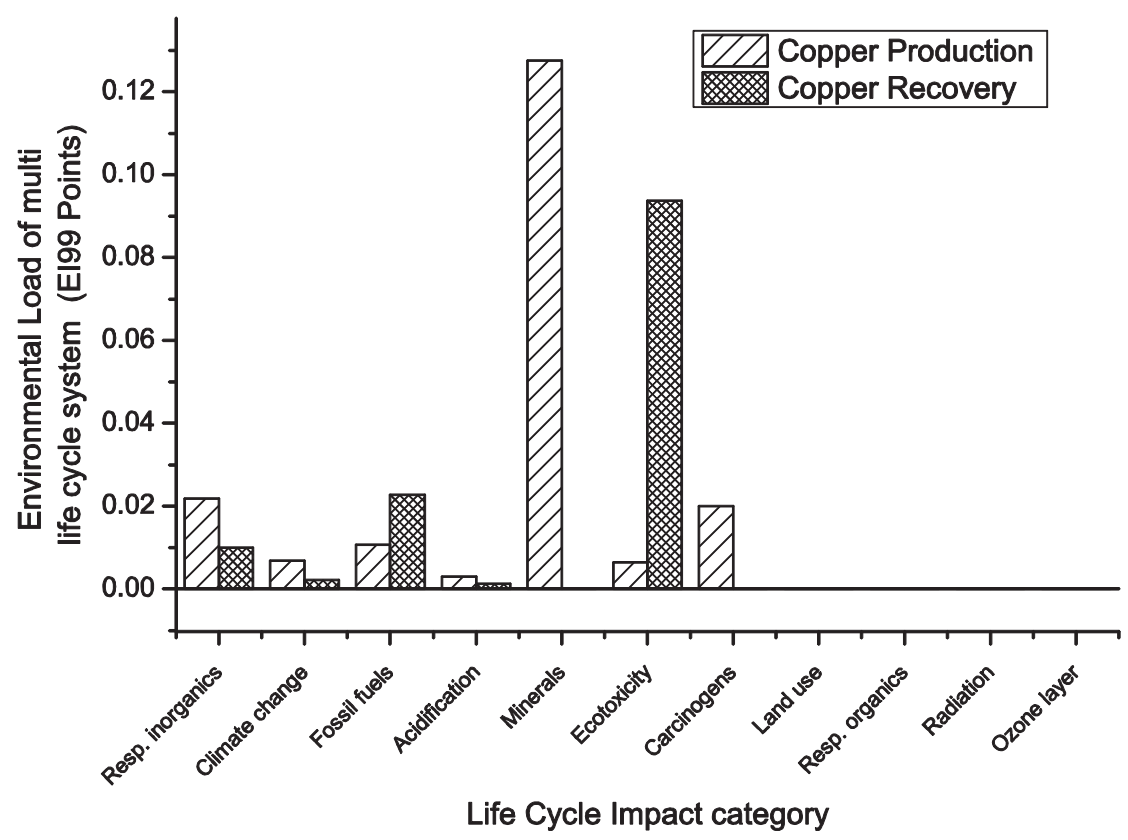

Fig. 6. Copper production and recovery environmental load.

product environmental load, compared with other display parts and other life cycle stages.

The environmental load is the highest in Scenario 2, followed by Scenario 1 and then Scenario 3, as shown in Fig. 8. The results indicate that, the faster the product updating frequency, the higher the environmental load of the entire product system. Although the LCD life cycle environmental load is intuitively lower than that of CRT, frequent replacement would increase the environmental load of the entire system rather than decrease it. From an environmental view, the service lifetime of CRT displays should be prolonged rather than being replaced by LCDs within its lifetime.

In MLCA, it is the same as the uncertainty assessment in traditional LCA. In LCA, uncertainties can be divided into 3 categories: parameter uncertainty when defining parameters, scenario uncertainty when selecting scenarios and model uncertainty when constructing mathematical models (Lloyd and Ries, 2007). In this case study, uncertainty of results mainly comes from the scenarios development including choice of recoverable materials and reusable components, as well as the settings of display products lifespan and products replacement frequencies. However, quantitative analysis cannot be performed fully because of present data quality, as most foreground data is from the investigation without confidence interval.

\section{Discussion}

As the above quantitative results show, technology innovation and product replacement will dramatically increase WEEE

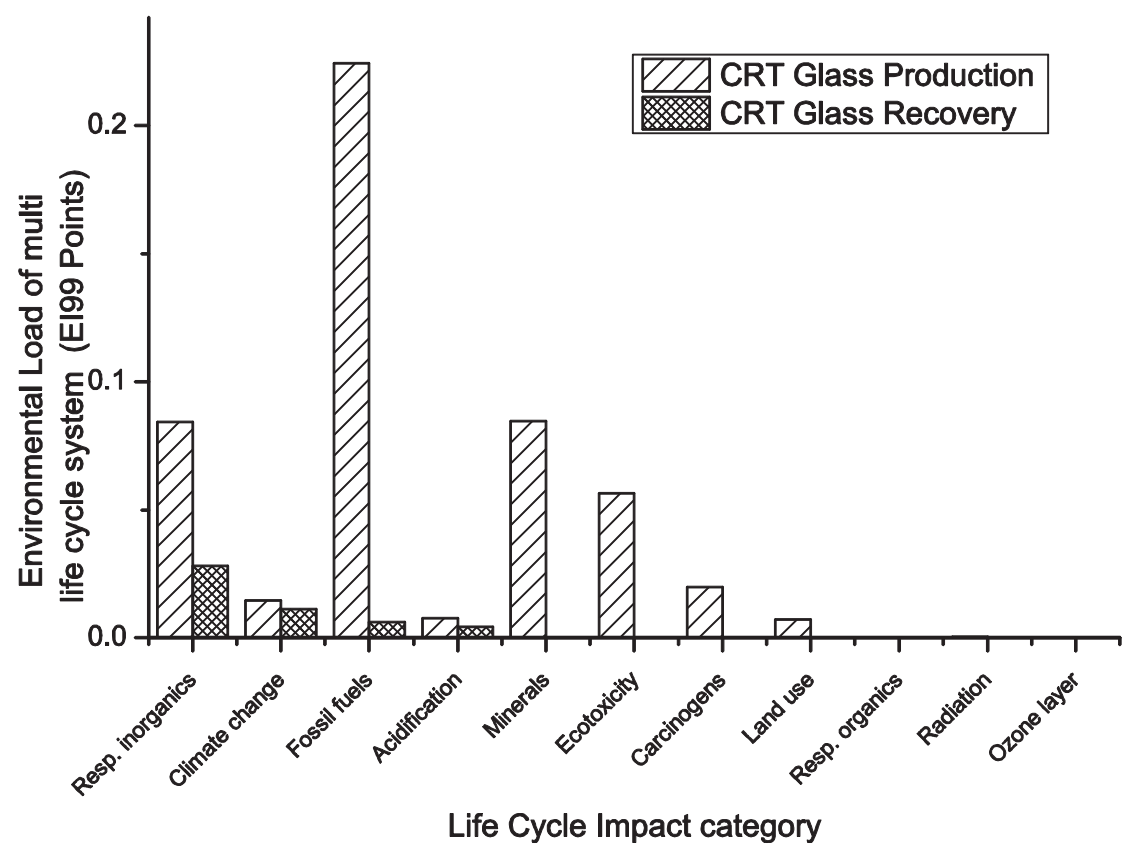

Fig. 7. CRT glass production and recovery environmental load. 


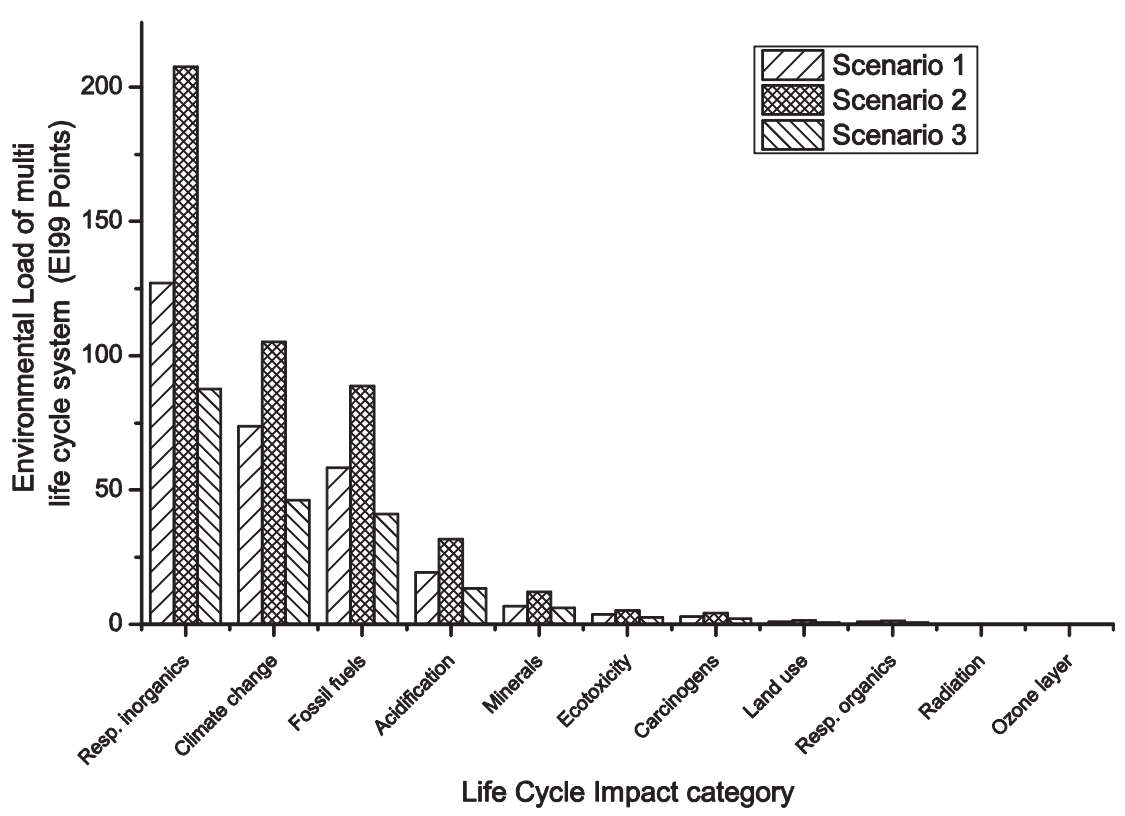

Fig. 8. Comparison of systematic environmental load in all three scenarios.

generation, and have considerable impacts on the multi-generation products system. Therefore, technology innovation and its effects should be further studied for a source reduction of WEEE and to decrease the environmental impact of the multi-generation products system. Furthermore, it is necessary to evaluate the effects of technology innovation when implementing eco-design strategies.

Based on the effects of technology innovation on the generation of WEEE, it may be possible to employ some marketing applications to help with a WEEE source reduction. Reducing the WEEE amounts does not mean controlling, or even preventing the development of product manufacturing technology. Rather, it should adjust technology trends based on a trade-off among the economic development, social welfare, and environmental loads. In the field of marketing, a company generally controls the timing of launching new products to optimize the composition of different kinds of products to get the maximum benefit. Similarly, effective WEEE management policies, such as planned obsolescence, can be an option to optimize WEEE management.

Besides waste management, the proposed methods in this paper will help improvement of sustainable consumption through integrating products replacement into product sustainability assessment. At present, eco-design focuses on one generation of product, without detailed consideration on the last or next generation of products, which may lead to unnecessary and frequent products replacement. As this case study of multi-generation display products shows, in a macro sense, eco-design should be integrated with eco-friendly marketing and other sustainable consumption strategies, to achieve the target of sustainable production and consumption.

However, when applying the methods proposed in this paper, there are some obstacles in practice, and corresponding measures are needed to tackle these issues.

Firstly, it is difficult to evaluate the impact of future technology innovation because of considerable uncertainty surrounding it. MLCA can be a way of regulating technology development trends and integrated with the marketing theory as a systematic analysis method. Thus technology innovation, especially in the information and communication technology field, is so fast and unpredictable that it is too difficult to forecast technical breakthroughs, let alone the environmental impact of future technologies. Furthermore, product diffusion is a type of marketing behavior that is difficult to control. Therefore, it is important for the MLCA model to be integrated with technology trend forecasts and sustainable marketing theories.

Secondly, part of key parameters for the proposed methods, including products replacement frequencies and real lifespans of products, are also always lack in the social statistics system and the existed basic LCA databases. So the operators of MLCA have to make reasonable assumptions or investigations themselves. For instance, there are not many studies on products replacement activities oriented from technology innovation to give typical scenarios for MLCA, so necessary interviews with the products consumers are necessary to get this information.

\section{Conclusions}

This paper uses case studies on technology innovation in display product systems to develop and apply WEEE generation estimation frameworks and MLCA methods.

The waste CRT glass estimations show that technology innovation with product replacements can greatly affect the WEEE generation amount and speed. If the product replacement is extremely fast, WEEE will increase dramatically in a short time, and then decreases rapidly. As a result, the waste management system will initially be under considerable pressure that may lead to a higher WEEE obsolescence rate, and treatment facilities may quickly become idle because of the speedy decrease in a later phase. Therefore, it is suggested that technology innovation and product replacements, should be incorporated during WEEE generation modeling.

Technology innovation can significantly affect the environmental impacts of multi-generation products systems. The MLCA method was developed and used to measure the environmental impact of such systems. The key contribution of MLCA is to evaluate the products system in which multi-generation products are linked by the materials or components cycle among different generation of products. The MLCA results of display products show that frequent replacement will increase the environmental burden of 
the entire product system, even when the new product has a lower life cycle environmental load. Therefore, the sustainable production and consumption policies should upgrade to include product development trends and replacement lifetime based on MLCA results, rather than solely focusing on the traditional static LCA for one generation of products.

\section{Acknowledgments}

We acknowledge the support of the National Natural Science Foundation of China (Grant Nos. 71303231, 71033005). This research is also carried out as a part of GREENet project which was supported by a Marie Curie International Research Staff Exchange Scheme Fellowship within the 7th European Community Framework Programme under Grant Agreement No. 269122. The paper reflects only the author's views and that the Union is not liable for any use that may be made of the information contained therein.

\section{References}

Bass, F.M., 1969. A new product growth for model consumer durables. Manag. Sci. $15,215-227$.

Cao, H., Folan, P., 2011. Product life cycle: the evolution of a paradigm and literature review from 1950-2009. Prod. Plan. Control 23, 641-662.

Caudill, R.J., Zhou, M., Yan, P., Lin, J., 2001. Multi-life cycle assessment: an extension of traditional life cycle assessment. In: Hundal, M.S. (Ed.), Mechanical Life Cycle Handbook: Good Environmental Design and Manufacturing. Marcel Dekker Inc., New York, USA, pp. 39-72.

Chen, Z., Liu, Y., 2000. Product multi life cycle engineering: background, present situation and prospects. J. Chongqing Inst. Technol. 14, 1-16.

Cooper, T., 2004. Inadequate life? Evidence of consumer attitudes to product obsolescence. J. Consum. Policy 27, 421-449.

Forster, P., Ramaswamy, V., Artaxo, P., Berntsen, T., Betts, R., Fahey, D.W., Haywood, J., Lean, J., Lowe, D.C., Myhre, G., Nganga, J., Prinn, R., Raga, G., Schulz, M., van Dorland, R., Bodeker, G., Boucher, O., Collins, W.D., Conway, T.J., Dlugokencky, E., Elkins, J.W., Etheridge, D., Foukal, P., Fraser, P., Geller, M., Joos, F., Keeling, C.D., Kinne, S., Lassey, K., Lohmann, U., Manning, A.C., Montzka, S., Oram, D., O'Shaughnessy, K., Piper, S., Plattner, G.K., Ponater, M., Ramankutty, N., Reid, G., Rind, D., Rosenlof, K., Sausen, R., Schwarzkopf, D., Solanki, S.K., Stenchikov, G., Stuber, N., Takemura, T., Textor, C., Wang, R., Weiss, R., Whorf, T., 2007. Changes in Atmospheric Constituents and in Radiative Forcing. Cambridge University Press, Cambridge, United Kingdom and New York, USA.

Fujimoto, H., Ahmed, A., 2001. Planning for product take-back and component life under uncertainty in technological evolution, environmentally conscious design and inverse manufacturing, 2001. In: Proceedings EcoDesign 2001: Second International Symposium on, pp. 37-42.

Granberg, B., 1997. The Quality Re-evaluation Process: Product Obsolescence in a Consumer-producer Interaction Framework. University of Stockholm, Department of Economic History, Stockholm.

Gregory, J.R., Nadeau, M.-C., Kirchain, R.E., 2009. Evaluating the economic viability of a material recovery system: the case of cathode ray tube glass. Environ. Sci. Technol. 43, 9245-9251.

Guo, Yuwen, L, J., Qiao, Qi, Liang, Jijun, Yang, Dongmei, Ren, Qian, 2011. Disposal and management of waste TFT-LCD. J. Environ. Eng. Technol. 1, 168-172.
Heiskanen, E., 1996. Conditions for Product Life Extension. National Consumer Research Centre, Helsinki.

Hester, R.E., Harrison, R.M., 2008. Electronic Waste Management. RSC Publisher, Cambridge, UK.

Huang, L., Xu, G., 2005. A primary study on multi-life cycle manufacturing. Environ. Technol. 1-4 (in Chinese).

King, A.M., Burgess, S.C., Ijomah, W., McMahon, C.A., 2006. Reducing waste: repair, recondition, remanufacture or recycle? Sustain. Dev. 14, 257-267.

Kostecki, M., 1998. The Durable Use of Consumer Products: New Options for Business and Consumption. Kluwer Academic Publisher, Dordrecht.

Kwak, M., Behdad, S., Zhao, Y., Kim, H., Thurston, D., 2011. E-waste stream analysis and design implications. J. Mech. Des. 133, 101003.

Lam, C.W., Lim, S.-R., Schoenung, J.M., 2012. Linking material flow analysis with environmental impact potential. J. Ind. Ecol. 17, 299-309.

Li, J., Wen, X., 2006. Recycling and Disposal Technologies for WEEE. China Environmental Science Press, Beijing, China.

Liu, Jingyong, S, S., Zeng, Xihui, Zhong, Sheng, Xie, Wuming, Wang, Yujie Zhong, Yuhua, Su, Qicheng, Li, Shenyong, 2014. Case research on the green recovery technologies and centralized treatment of waste electronic and electric equipments. Renew. Resour. Recycl. Econ. 7, 34-39.

Li, Liuen, Wei, Jia, Limin, Cang, Wang, Tianyu, Honggang, Cao, Hu, L., 2007. In: P.R.C. S.I.P.O.o.t. (Ed.), A Type of Recovery Technology for Obsolete Monitor Glass Shell. China.

Lloyd, S.M., Ries, R., 2007. Characterizing, propagating, and analyzing uncertainty in life-cycle assessment: a survey of quantitative approaches. J. Ind. Ecol. 11, $161-179$.

Michalakelis, C., Varoutas, D., Sphicopoulos, T., 2010. Innovation diffusion with generation substitution effects. Technol. Forecast. Soc. Change 77, 541-557.

Norton, J.A., Bass, F.M., 1987. A diffusion theory model of adoption and substitution for successive generations of high-technology products. Manag. Sci. 33, 1069-1086.

OECD, 1982. Product Durability and Product-life Extension. Organisation for Economic Co-operation and Development., Paris.

Pialot, O., Millet, D., Tchertchian, N., 2012. How to explore scenarios of multiple upgrade cycles for sustainable product innovation: the "Upgrade Cycle Explorer" tool. J. Clean. Prod. 22, 19-31.

Quariguasi-Frota-Neto, J., Bloemhof, J., 2012. An analysis of the eco-efficiency of remanufactured personal computers and mobile phones. Prod. Oper. Manag. 21, $101-114$.

Rose, C., Ishii, K., Stevels, A., 2002a. Influencing design to improve product end-oflife stage. Res. Eng. Des. 13, 83-93.

Rose, C.M., Stevels, A., Ishii, K., 2002b. Method for formulating product end-of-life strategies for electronics industry. J. Electron. Manuf. 11, 185-196.

Van Nes, N., Cramer, J., 2006. Product lifetime optimization: a challenging strategy towards more sustainable consumption patterns. J. Clean. Prod. 14, 1307-1318.

Walk, W., 2009. Forecasting quantities of disused household CRT appliances - a regional case study approach and its application to Baden-Württemberg. Waste Manag. 29, 945-951.

Widmer, R., Oswald-Krapf, H., Sinha-Khetriwal, D., Schnellmann, M., Böni, H., 2005. Global perspectives on e-waste. Environ. Impact Assess. Rev. 25, 436-458.

Wu Jian, H.Y., Feng, Hong, 2013. Treatment of waste LCD and recycling technology of indium. Sichuan Environ. 32, 122-128.

Yang, Y., Williams, E., 2009. Logistic model-based forecast of sales and generation of obsolete computers in the U.S. Technol. Forecast. Soc. Change 76, 1105-1114.

Zhao, Y., Pandey, V., Kim, H., Thurston, D., 2010. Varying life cycle lengths within a product take-back portfolio. J. Mech. Des. 132, 091012.

Zhuang, C., 1999. Research on products chain model of product multi-life cycle decision making technology. In: Proceedings of Chinese 5th Conference on Computer Aided Manufacture Management, Chongqing, China. 